\title{
Monitoring the changes in impervious surface ratio and urban heat island intensity between 1987 and 2011 in Szeged, Hungary
}

\author{
László Henits • László Mucsi • Csilla Mariann Liska
}

Received: 23 February 2016 / Accepted: 11 January 2017 /Published online: 31 January 2017

(C) Springer International Publishing Switzerland 2017

\begin{abstract}
Landsat time series data make it possible to continuously map and examine urban land cover changes and effects on urban environments. The objectives of this study are (1) to map and analyse an impervious surface and its changes within a census district and (2) to monitor the effects of increasing impervious surface ratios on population and environment. We used satellite images from 1987, 2003 and 2011 to map the impervious surface ratio in the census district of Szeged, Hungary through normalized spectral mixture analysis. Significant increases were detected from 1987 to 2011 in industrial areas (5.7-9.1\%) and inner residential areas (2.5-4.8\%), whereas decreases were observed in the city centre and housing estates due to vegetation growth. Urban heat island (UHI) values were derived from the impervious surface fraction map to analyse the impact of urban land cover changes. In 2011, the average value in the industrial area was $1.76^{\circ} \mathrm{C}$, whereas that in the inner residential area was $1.35-1.69^{\circ} \mathrm{C}$. In the city centre zones and housing estates, values ranging from 1.4 to $1.5^{\circ} \mathrm{C}$ and from 1.29 to $1.5^{\circ} \mathrm{C}$, respectively, were observed. Our study reveals that long-term land cover changes can be
\end{abstract}

\footnotetext{
L. Henits $(\bowtie) \cdot$ L. Mucsi $\cdot$ C. M. Liska

Department of Physical Geography and Geoinformatics, University of Szeged, Szeged, Hungary

e-mail: henits@geo.u-szeged.hu

L. Mucsi

e-mail: mucsi@geo.u-szeged.hu

C. M. Liska

e-mail: csliska@geo.u-szeged.hu
}

derived at the district level from Landsat images and that their effects can be identified and analysed, providing important information for city planners and policy makers.

Keywords Impervious surface ratio · Landsat time series data - Urban heat island - Spectral mixture analysis · Land cover change $\cdot$ Census data

\section{Introduction}

Over $50 \%$ of people worldwide $(53.6 \%)$ currently live in urban areas and in 2050, the urban population is expected to reach $67 \%$ (United Nations 2014). In Hungary, 70.8\% of the total population lives in urban areas (United Nations 2014). As global urbanization progresses rapidly, it is becoming more important to understand its temporal and spatial dynamics for urban environment improvement (Michishita et al. 2012). Remote sensing is an adequate tool to monitor urban growth and land cover changes over the last 30 years (Geymen and Baz 2007; Schneider 2012). The conversion of land cover types and the reduction of agricultural land, forest, wetland and water bodies can be detected using long-term satellite (e.g. Landsat) time series data (Dewan and Yamaguchi 2009; Henits et al. 2016). These land transformations modify different environmental variables, resulting in the development of urban heat islands and the degradation of human and environmental health (Sharma et al. 2013).

Mapping urban areas based on medium or low spatial resolution remote sensing data is a complex problem 
because urban features occur in various sizes and forms, which can lead to different "mixtures" within a pixel that represents a given area (Small and Lu 2006). Mixed pixels significantly impact the effective use of remote sensing data in mapping urban land cover and land use types (Cracknell 1998). Traditional pixel-based classification methods, such as maximum likelihood or unsupervised classification, cannot effectively handle less densely built-up zones in urban areas due to the large number of mixed pixels (Lu and Weng 2006a).

In 1995, Ridd proposed the vegetation-impervious surface-soil (V-I-S) model for the parameterization of urban environment biophysical composition. According to this conceptual model, the most representative components of an urban ecosystem may be the linear combination of vegetation, impervious surfaces and soils. Numerous researchers have used Landsat data for mapping impervious surfaces based on Ridd's V-I-S model. This led to the development of several new classification methods in urban remote sensing, including spectral mixture analysis (Wu and Murray 2003; Franke et al. 2009), regression models (Bauer et al. 2007), decision trees (Setiawan et al. 2006), subpixel classifications (Bauer et al. 2007) and neural networks (Chormanski et al. 2008; Weng and $\mathrm{Hu}$ 2008).

Spectral mixture analysis (SMA) has been widely used in many fields to derive the ratio of representative land cover types because it is a physically based image analysis tool that provides quantitative results and is effective for addressing the problem of mixed pixels (Lu and Weng 2006a; Michishita et al. 2012). Small (2002) described the urban landscape with a threecomponent linear mixture model (high albedo, low albedo and vegetation) in New York City. Wu (2004) developed a normalized spectral mixture analysis to reduce the brightness variation effect of urban land covers and to quantify urban composition under the framework of the V-I-S model. Lu and Weng (2006a) used spectral mixture analysis to extract impervious surface information in the city of Indianapolis and then classified urban land use by combining impervious surface information with population density data. Although spectral mixture analysis is a popular method to derive urban surface components, only a few multitemporal studies have utilized this technique for urban land cover changes (Rashed et al. 2005; Michishita et al. 2012).

Urban land cover change has a significant impact on increasing urban heat island (UHI) phenomena. Generally, higher atmospheric and surface temperatures occur in urban areas than in surrounding areas (Vogt and Oke 2003). Differences in UHI intensity values are related to land use and land cover types and their changes, e.g. the amount of built-up areas and their changes (Chen et al. 2006). Numerous studies used the relationship between land surface temperature (LST) and a variety of indicators derived from remotely sensed data to examine the UHI phenomenon (Deng and $\mathrm{Wu} 2013$ ). Linear regression models have been built between LST and different biophysical factors, such as a normalized difference vegetation index (NDVI) (Zhang and Wang 2008), impervious surface abundance (Imhoff et al. 2010), land cover and land use types (Xian and Crane 2006) and landscape metrics (Li et al. 2011).

Integration of remote sensing and population census data is performed more frequently in urban studies. The residential population and the quality of their lives can be determined by using space-borne satellite images with statistical data (Elvidge et al. 1997; Lu et al. 2006; Lo and Faber 1997; Li and Weng 2007), and the accuracy of urban land use classification can be improved (Mesev 1998; Lu and Weng 2006a). Population census data and impervious surface information were used in our study for the following reasons: (1) analysing land cover changes in smaller administrative zone units instead of the entire city area, (2) comparing the statistical parameters (average impervious surface area and UHI values) of different land use categories and (3) monitoring the effects of increasing impervious surface ratios and their negative effect on the population and the environment.

\section{Methods}

Study area

Szeged is the third largest city in Hungary $(170,052$ inhabitants, Hungarian Central Statistical Office 2012) and is the regional centre of the Southern Great Plain region. The administrative area of the city is $281 \mathrm{~km}^{2}$, whereas the suburban and urban regions are restricted to an area of $45-50 \mathrm{~km}^{2}$. The city is divided by the Tisza River. The current radio-concentric structure of Szeged was reconstructed after the flood of 1879 , following the example of Paris, Pest and Vienna city structures. Ninety-five percent of the city buildings were destroyed by the flood of 1879 . To protect the city, a $12-\mathrm{km}$ long dam was built connecting the upper bank of the Tisza 
River to the lower bank of the Tisza River, enclosing the city in a half circle. Construction sites restricted to this area thus established the future development of the city (Blazovich 2005).

The Hungarian Central Statistical Office (KSH) differentiated nine functional categories in the area of Szeged (Fig. 1). Their appearance is concentric around the core of the city and independent features in outlying areas can be differentiated.

\section{Data}

Landsat Thematic Mapper (Landsat TM) satellite images acquired during summer months from 1987 to 2011 (8 July 1987, 4 June 2003, 10 July 2011) were used for the study. Impervious surfaces from images acquired in summer achieved the best results based on spectral mixture analysis (Wu and Yuan 2007). The preprocessing stage can accommodate uncertainty factors in using multitemporal images for change detection analysis, including the effects of atmosphere, topography, phenology and sun view angles. These effects can be eliminated or reduced by using the same satellite sensor, same radiometric resolution and coincident seasonal acquisition dates (Song and Woodcock 2003). Landsat TM images have seven spectral bands with $30-\mathrm{m}$ spatial resolution (in the case of thermal infrared, 60-m spatial resolution). The satellite images were downloaded from the U.S. Geological Survey (USGS) Landsat archive website (http://glovis.usgs.gov). The most important and essential procedure for change detection analysis is the precise image registration and radiometric correction (Jianyaa et al. 2008). The Landsat images were available in the Universal Transverse Mercator (UTM) projection system (WGS84 ellipsoid, Zone N34) and were then reprojected to the Hungarian National Projection System (EOV) by a second-degree polynomial transformation. For resampling, the nearest neighbour method was applied. The root mean square error (RMS) was found to be less than 0.5 in each case. The digital numbers (DNs) of the Landsat TM images were converted to reflectance values by atmospheric correction following the methods proposed by Chavez (1996) and by Chander and Markham (2003).

Spectral mixture analysis

Land cover within a pixel can be calculated by the application of spectral mixture analysis (SMA). This method involves modelling mixed pixels as a combination of pure land cover types called endmembers (Roberts et al. 1998). The SMA method can be divided into linear and nonlinear spectral mixture analysis depending on the complexity of scattering. Multiple scattering caused by canopy, vegetation or soil may have significant effects on the calculation of land cover in the nonlinear case (Borel and Gerstl 1994). If the mixing between endmember spectra is mainly linear and endmembers are known, the fraction of each endmember can be accordingly estimated (Adams et al. 1986; Smith et al. 1990). The linear SMA model is typically more effective for application in urban areas (Wu and Murray 2003).

Linear spectral mixture analysis (LSMA) calculates the fraction of each land cover type in each pixel by using a minimum of two and a maximum of six endmembers (in the case of Landsat TM). Each endmember represents a pure land cover type (Wu and Murray 2003). Linear spectral mixture analysis can be described as follows:

$R_{b}=\sum_{i=1}^{N} f_{i} \times R_{i, b}+\varepsilon_{b}$,

where

$R_{b}$ is the reflectance value of the image in band $b$,

$N \quad$ is the number of endmembers,

$f_{i} \quad$ is the fraction of endmember $i$,

$R_{i b} \quad$ is the reflectance value of endmember $i$ in band $b$,

$\varepsilon_{b} \quad$ is the residual error value.

The sum of the endmember factors are 1 for each pixel and if $f_{i} \geq 0$.

$\sum_{k=1}^{n} f_{i, k}=1$

Suitability of the model is assessed by the $\varepsilon_{b}$ residual member or by the RMS of all image bands.

RMSE $=\frac{\sqrt{\sum_{i=1}^{n} \varepsilon_{i}^{2}}}{n}$

We used normalized spectral mixture analysis (NSMA) developed by Wu (2004) in our study. Impervious surfaces, vegetation and soil were the three endmembers selected and spectral mixture analysis was applied after the normalization process. Normalization can reduce or eliminate brightness variability within 
a)

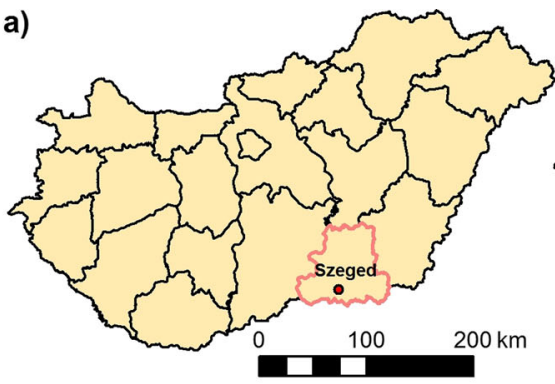

$19^{\circ} 40^{\prime}$ E $19^{\circ} 50^{\prime}$ E $20^{\circ} 0^{\prime}$ E 20 $20^{\circ}$ E $20^{\circ} 20^{\prime}$ E 20 $20^{\circ} 30^{\prime}$ E $20^{\circ} 40^{\prime}$ E

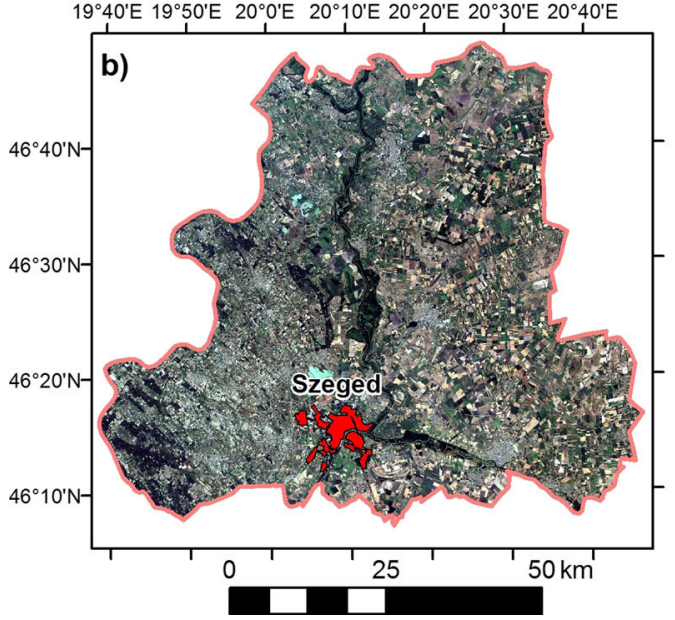

c)

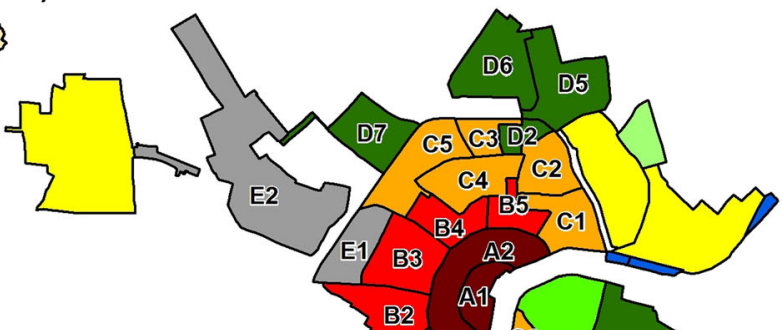

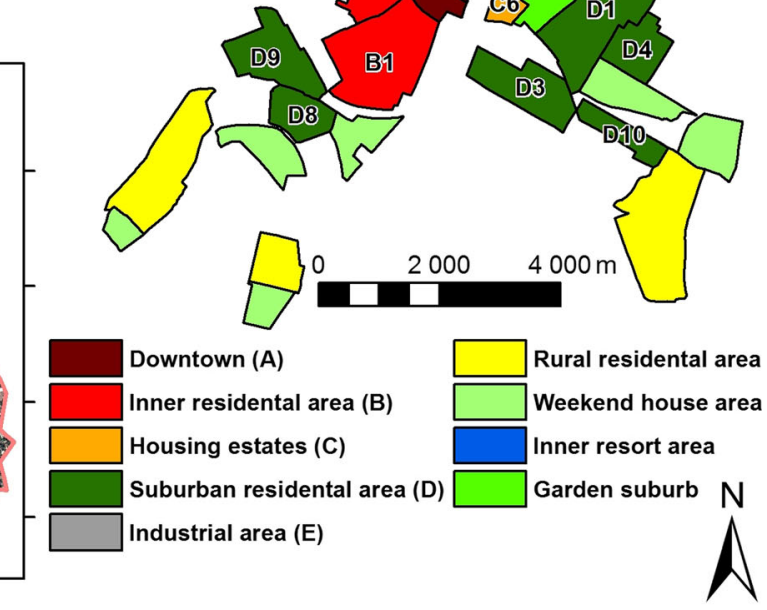

Fig. 1 Study area. a Hungary. b Location of Szeged in the county of Csongrad. $\mathbf{c}$ The census district of Szeged

each urban component; thus, each V-I-S component can be represented by a single endmember (Wu 2004). The normalization method can be described by the following equation:

$\bar{R}_{b}=\frac{R_{b}}{\mu} \times 100$,

where

$\mu=\frac{1}{N} \times \sum_{b=1}^{N} R_{b}$,

where $\overline{R_{b}}$ is the normalized reflectance value of the pixel in band $b, R_{b}$ is the original reflectance value in band $b$, $\mu$ is the average reflectance values for the pixel for all bands and $N$ is the number of bands (for Landsat TM it is 6).

Endmembers are usually selected directly from different bands of satellite images or from 2D feature space of transformed images (Rashed et al. 2001). Image endmembers can be selected more easily from feature spaces derived from principal component analysis (PCA) bands because PCA compresses nearly $90 \%$ of data variance into the first two or three bands and minimizes the correlation between the bands (Smith et al. 1985). Fig. 2 shows the vegetation, soil and impervious surface endmembers in the feature space representation of the first three principal component bands.

The results of NSMA are fraction images showing the spatial distribution of land cover types within a pixel. Pixel values are between 0 and 1 . If the value is 1 , the fraction of a given land cover type is $100 \%$ within that pixel (Fig. 3).

\section{Change detection analysis}

Fraction images of the land cover types were derived from three Landsat TM images (8 July 1987, 4 July 2003 and 10 July 2011) by the threeendmember (impervious surface, vegetation, soil) normalized spectral mixture analysis method. Pure pixels representing a homogeneous spectrum were individually selected in feature spaces derived from the corresponding satellite images. The same endmembers were used for each normalized spectral mixture analysis. The group of pixels selected from three points of time were intersected and 

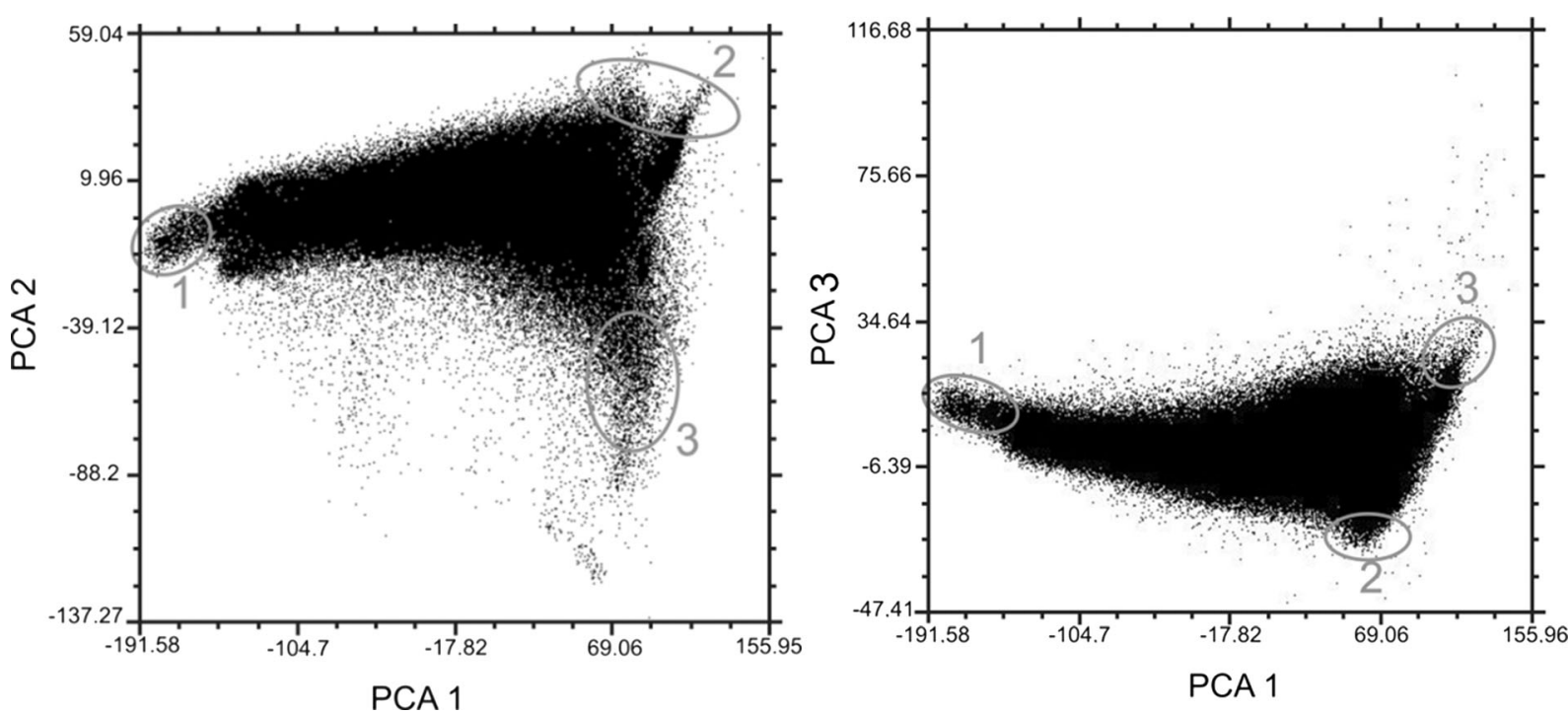

Fig. 2 Endmembers of 1 vegetation, 2 soil and 3 impervious surfaces in a feature space representation of the first three principal component bands

there was no intersection of the three endmember sets in the case of soils. Therefore, pixels collected from individual images and representing pure soils were used for spectral mixture analysis. Fraction images showing the ratio of impervious surfaces within a pixel are illustrated in Fig. 4.

Impervious surface fraction maps from 4 July 2003 and 8 July 1987, then from 10 July 2011 and 4 July 2003 were subtracted in the change detection analysis (Fig. 5). First, pixel-based changes were analysed for the city area with the difference maps, and then district-level changes were examined by zone statistics. Five categories were separated on the difference maps: changes less than $10 \%$ both in positive and negative ranges were considered to be unchanged, changes between 10 and $25 \%$ meant lower changes and differences of more than one fourth of a pixel (i.e. more than $25 \%$ ) were considered to be high changes. Zone-statistic changes less than $1 \%$ fell into the unchanged category, lower changes were between 1 and $5 \%$ and differences of more than $5 \%$ were categorized as high changes (Fig. 6).

Modelling urban heat island intensity

In our study, we used the linear regression equation developed by Unger et al. (2000) to map the spatial distribution of UHI in Szeged. The UHI intensity data were collected by mobile observations from March 1999 a)

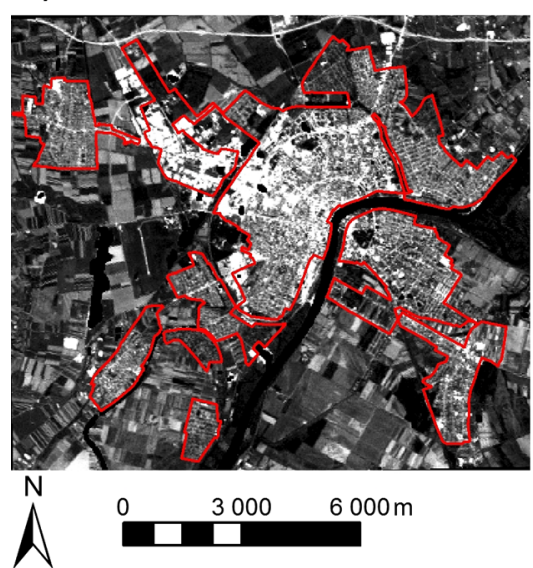

b)

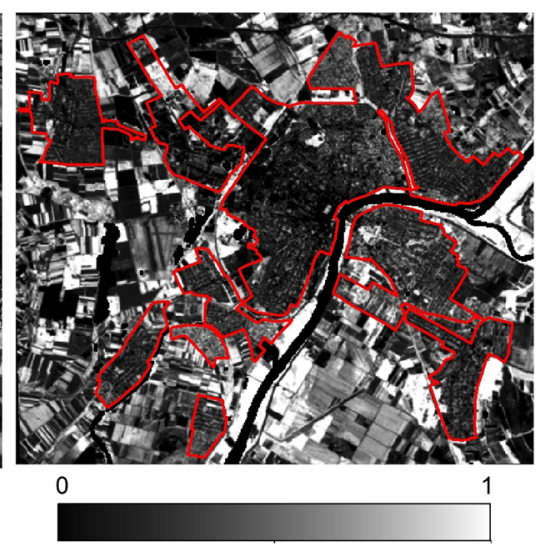

c)

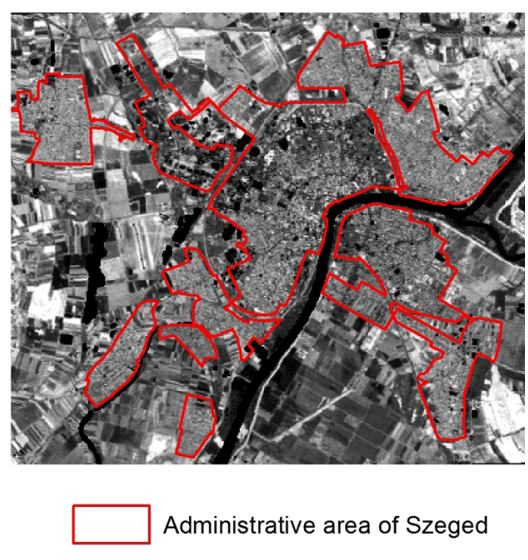

Fig. 3 Fraction images of a impervious surface, $\mathbf{b}$ vegetation and $\mathbf{c}$ soil 
a)

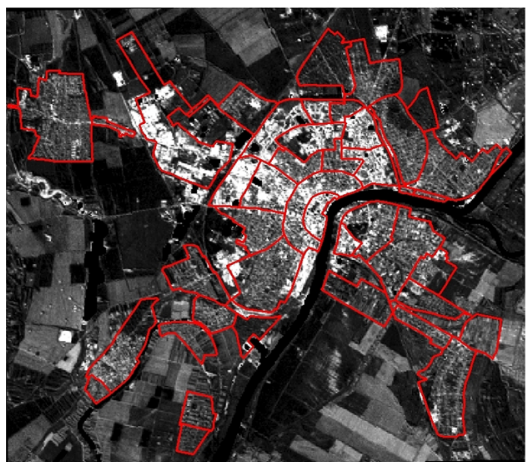
N

$\Lambda$ b)

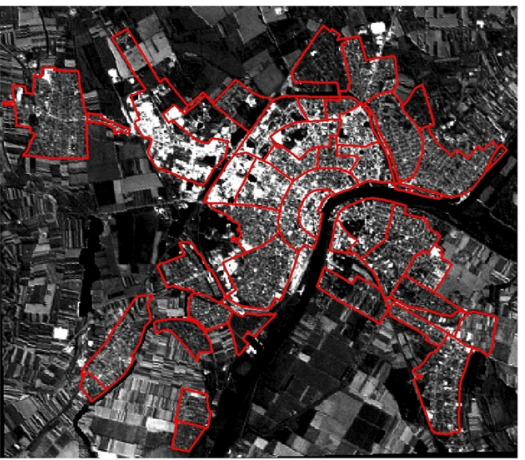

0 c)

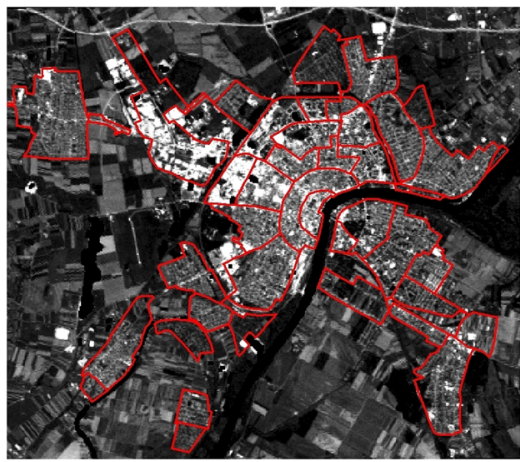

Census districts of Szeged

Fig. 4 Fraction images showing the ratio of impervious surfaces derived from images acquired on a 8 July 1987 , b 4 July 2003 and c 10 July 2011

to February 2000. The study area was divided into $500 \mathrm{~m} \times 500$-m square grid cells (107 samples) covering the urban and suburban parts of Szeged. Measurements were made by workers at the Department of Climatology and Landscape Ecology at the University of Szeged using a car. Unger et al. (2000) modelled the average of maximum UHI intensity during the nonheating period (16 April-15 October) in Szeged by a linear regression equation containing the measured

a)
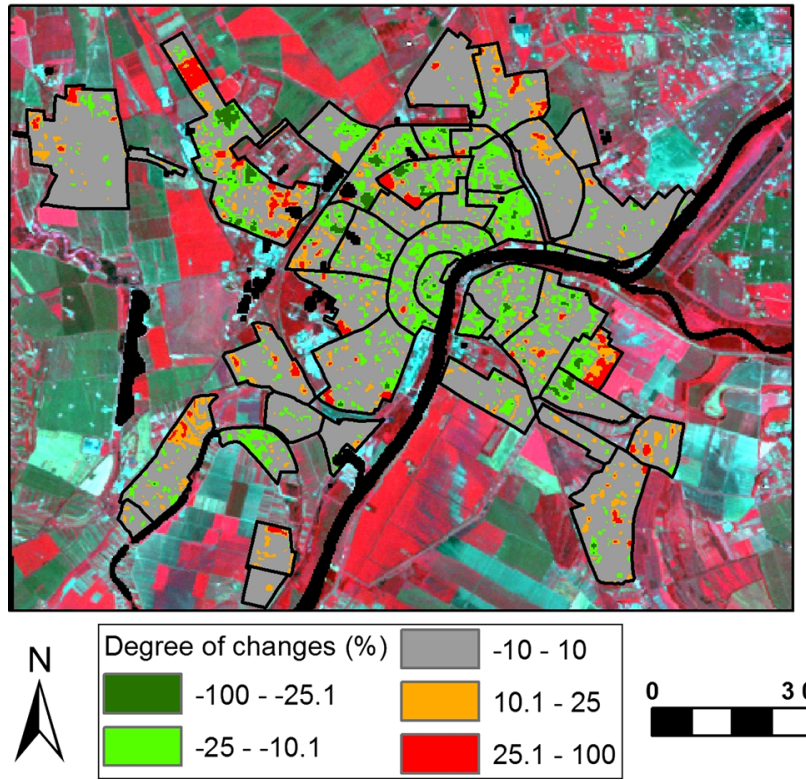

maximum value of urban heat island intensity and the ratio of built-up surface as a percentage:

$\Delta T=0.018 \times B+0.716$,

where

$\Delta T$ is the average of maximum UHI intensity

$B \quad$ is the ratio of built-up areas as a percentage b)
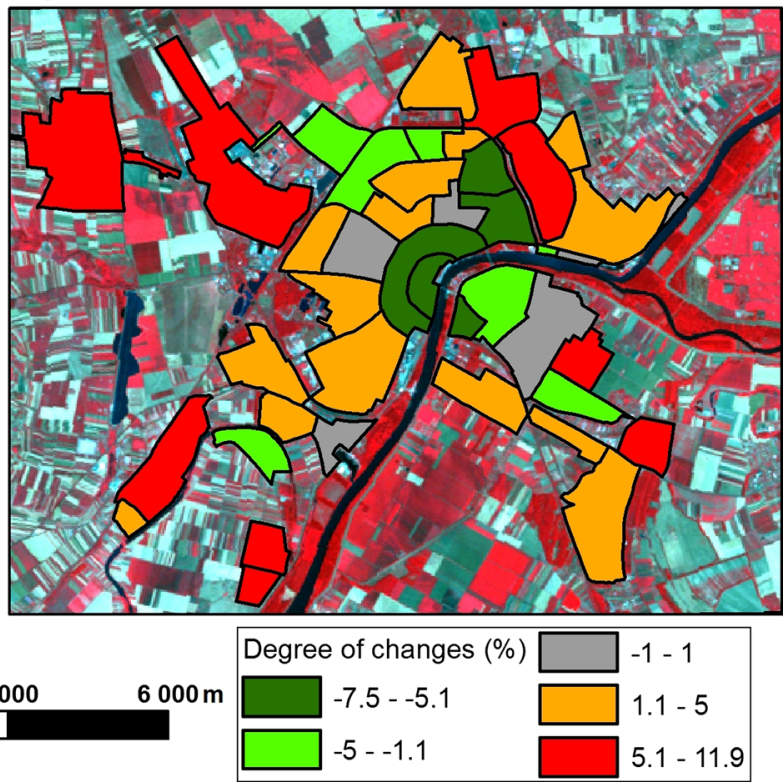

Fig. 5 Changes in the ratio of impervious surfaces between 1987 and 2003: a difference map and $\mathbf{b}$ a map representing the average changes in each zone 
a)
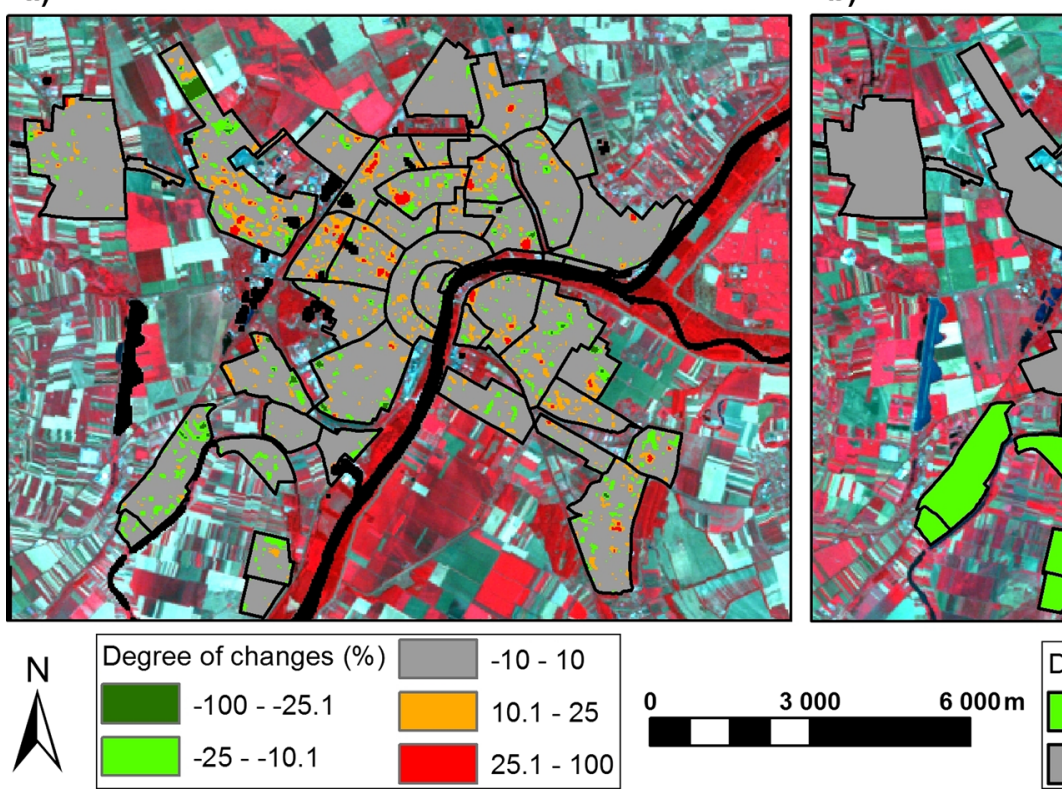

b)

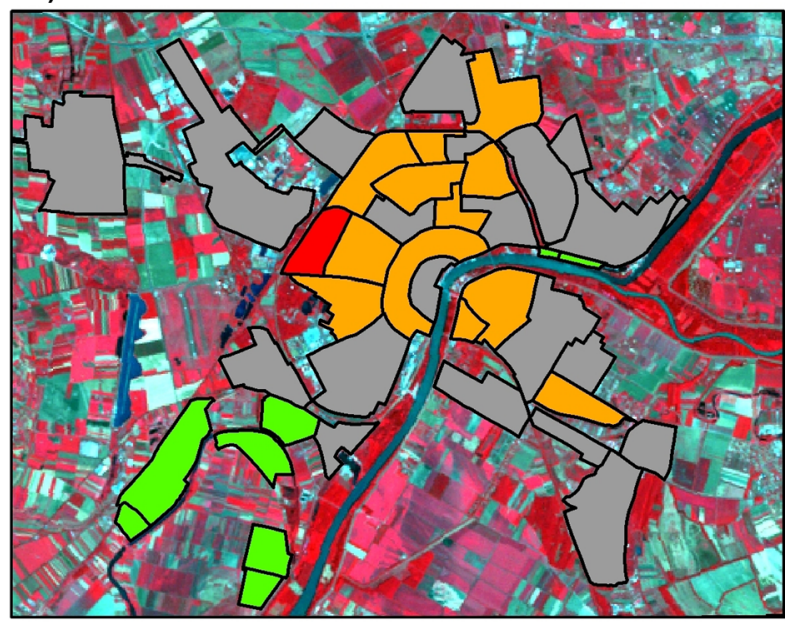

Fig. 6 Changes in the ratio of impervious surfaces between 2003 and 2011: a difference map and $\mathbf{b}$ a map representing the average changes in each zone

In our study, the impervious surface fraction maps were used as input data to this equation. The average value of built-up areas as a percentage was assigned to the centre point of each $500 \mathrm{~m} \times 500$-m grid cell, and the estimated UHI intensity values were calculated using the linear regression equation. Maps showing the spatial distribution of the mean maximum UHI intensity were created with the spline interpolation method (Fig. 7).

\section{Results}

Analysis of land cover type changes at the district level (1987-2011)

Average impervious surface ratios for KSH districts were calculated using the impervious surface fraction maps derived from the three multispectral images. The changes in impervious surface ratios are shown for different built-up categories from 1987 to 2011 (Fig. 5).

Two major trends can be observed in the changes between 1987 and 2003. The first is the decrease in impervious surface ratios in the city centre and in the housing estates. The average decreases in the city centre were 5 and $5.4 \%$ (A1 and A2, respectively), whereas in the five zones of the housing estates, the decrease ranged from $1.7-7.6 \%(\mathrm{C} 1-$ C6). These values do not indicate a decrease in the ratio of built-up density. In the former case, the covering effect of the growing canopy causes this problem. In the latter case, the value indicates the formation of open green areas between buildings after the 1980s when construction was completed. The second trend is the increase in impervious surface ratios in the inner residential areas, in the industrial areas and in the suburban zones. The average increase was $2.1-4.3 \%$ in three zones of the residential area $(\mathrm{B} 1, \mathrm{~B} 2, \mathrm{~B} 4)$, whereas there were no significant changes in the other two zones (B3, B5). The average impervious surface ratio increased by 2.5 and $5.1 \%$ in industrial areas (E1 and E2, respectively). In suburban residential areas, the ratio increased by $1.1-7.5 \%$ in eight out of ten zones because people moved to the peripheral regions of the city where housing had increased.

Significant changes in land cover types occurred in the inner residential areas, in the housing estates and in the industrial zones between 2003 and 2011 (Fig. 6). There were increases in impervious surface ratios in the inner residential areas of $1.7,3.8$ and $3 \%$ in zones $\mathrm{B} 2, \mathrm{~B} 3$ and $\mathrm{B} 4$, respectively. There were minor ratio increases of $1-5 \%$ in the housing 
a)

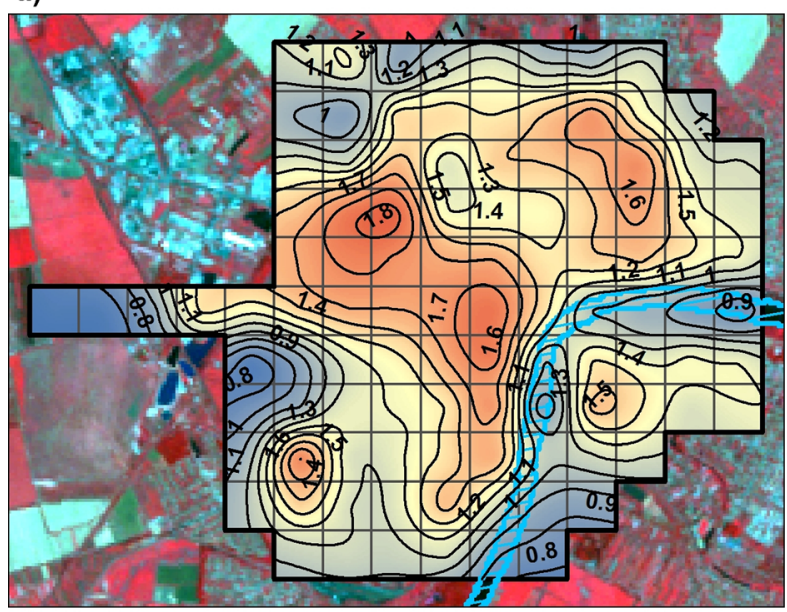

b)

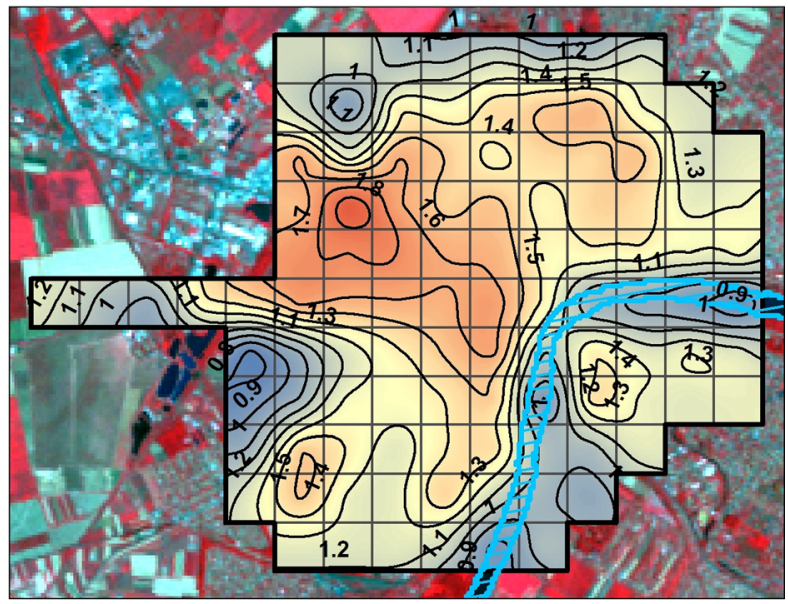

c)
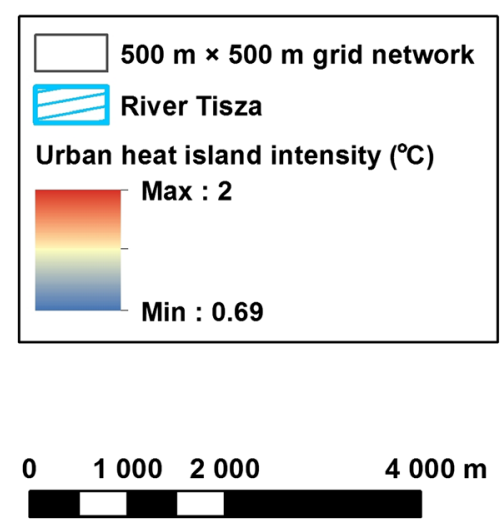
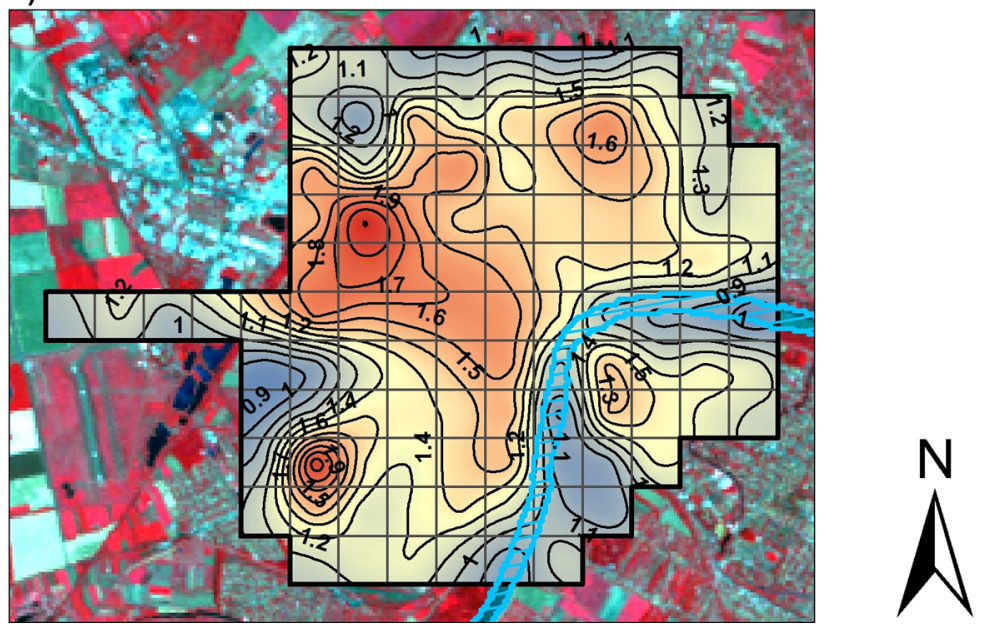

Fig. 7 Maps showing the spatial distribution of the mean maximum UHI intensity derived from fraction maps of impervious surfaces in a 1987, b 2003 and c 2011

estate zones. In zone $\mathrm{C} 2$, the increase was $4 \%$; in zone $\mathrm{C} 5$, the increase was $2.4 \%$; and in zone $\mathrm{C} 6$, the increase was $2.6 \%$. The change in the impervious surface ratios was $6.6 \%$ in the industrial area contained within the round dam (E1), whereas in zone E2, the change was under $1 \%$. Only minor differences occurred in the city centre and suburban residential areas compared with 2003, with less than a $1 \%$ increase or decrease in most cases. By 2011, the ratio of impervious surfaces reached 50 and $44.3 \%$ in the city centre zones, and $35.1-43.4 \%$ in four zones and $55.2 \%$ in one zone in the inner residential areas. Housing estates and suburban residential areas can be characterized by values ranging from 36 to $47.2 \%$ and from 19 to $36 \%$, respectively (Fig. 8).
Analysis of urban heat island intensity change (1987-2011) (Fig. 7)

Urban heat island intensity values were analysed only in districts that were included in the temperature measurement grid network. Consequently, in the industrial area, only one district (E1) was analysed and none of the suburban residential areas were analysed.

The highest average UHI values were measured in the industrial districts and inner residential areas. In 2011, the average value in the industrial area was $1.76^{\circ} \mathrm{C}$, whereas in districts $\mathrm{B} 3$ and $\mathrm{B} 4$ of the inner residential area, the values were $1.69{ }^{\circ} \mathrm{C}$ and $1.52{ }^{\circ} \mathrm{C}$, respectively. In the city centre and in the housing estates, 1.4-1.5 ${ }^{\circ} \mathrm{C}$ and $1.29-1.5^{\circ} \mathrm{C}$ values, respectively, were observed. 


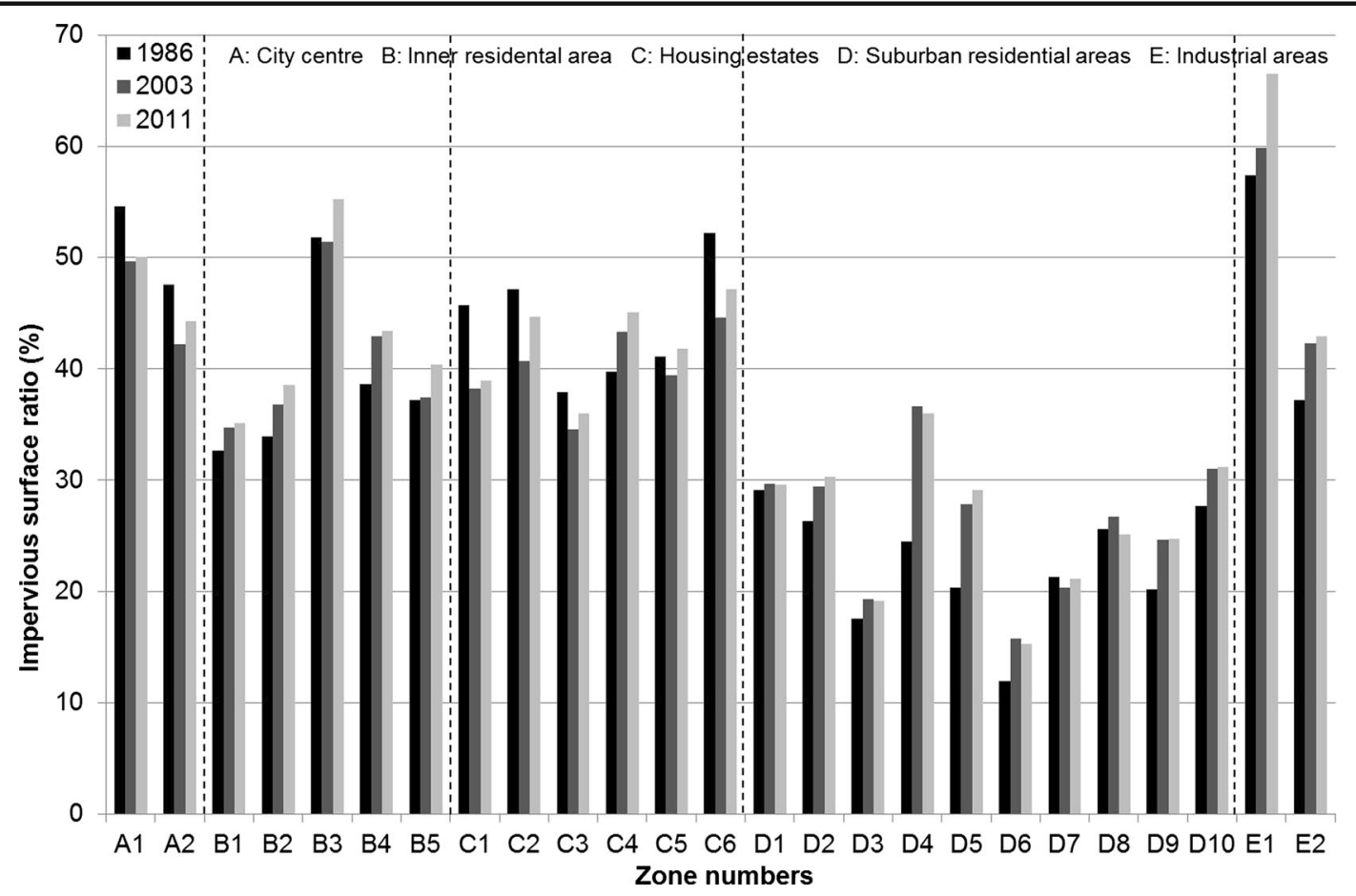

Fig. 8 Average ratios of impervious surfaces in the $a$ city centre, $b$ inner residential areas, $c$ housing estates, $d$ suburban residential areas and $e$ industrial areas in 1987, 2003 and 2011

The UHI value increased in the inner residential areas between 1987 and 2011. In districts B1, B2 and B4, the increases were $0.02,0.03$ and $0.08{ }^{\circ} \mathrm{C}$, respectively, from 1987 to 2003 , whereas values increased further by $0.03,0.04$ and $0.01{ }^{\circ} \mathrm{C}$ by 2011 , respectively. In districts $\mathrm{B} 3$ and $\mathrm{B} 5$, the average values decreased from 1987 to 2003; however, by 2011, the temperatures increased by 0.04 and $0.01{ }^{\circ} \mathrm{C}$ from 1987 , respectively. In the city centre, a decrease of $0.09{ }^{\circ} \mathrm{C}$ was found, followed by minor increases $\left(0.01\right.$ and $\left.0.04{ }^{\circ} \mathrm{C}\right)$. Values decreased in districts $\mathrm{C} 1, \mathrm{C} 2, \mathrm{C} 3$ and $\mathrm{C} 6$ of the housing estates between 1987 and 2013. In the former case, there was a decrease of $0.11^{\circ} \mathrm{C}$, whereas in the latter case, there was a decrease of $0.07{ }^{\circ} \mathrm{C}$. An increase $\left(0.07^{\circ} \mathrm{C}\right)$ and no change $\left(0^{\circ} \mathrm{C}\right)$ were observed in the other two districts ( $\mathrm{C} 4$ and $\mathrm{C} 5$, respectively). UHI increased by $0.07{ }^{\circ} \mathrm{C}$ and then by an additional $0.08^{\circ} \mathrm{C}$ in the industrial areas (E1) by 2011 (Fig. 9).

\section{Discussion}

Results show that district-level impervious surface and urban heat island time series data can be derived from Landsat TM data through spectral mixture analysis and regression analysis. In the past decades, different change detection methods have been developed based on requirements and criteria. However, the selection and application of the most suitable method are difficult in practice (Lu et al. 2004). In our study, spectral mixture analysis was applied because previous studies had confirmed that the traditional pixel-based classification methods, such as maximum likelihood, were not suitable for handling complex urban landscape and mixed pixels (Lu and Weng 2006b). This method had previously been used in change analyses of urban areas, but in previous studies, the impervious surface ratios were determined for the entire city (Weng and Lu 2008; Yuan and Bauer 2007; Yuan et al. 2008) or for certain land use categories (Madhavan et al. 2001). Values calculated for different functional districts, together with population census data, provide information about the characteristics of certain built-up types. Condominium construction started in the 1990s in inner residential areas and housing estates could be detected by analysing the average impervious surface ratios in certain districts (Figs. 5 and 6). Furthermore, the construction of malls, shopping centres and commercial and service provider buildings occupying large areas can be detected on difference maps. In some cases, the impervious surface 
Fig. 9 Average urban heat island intensity values in the $a$ city centre, $b$ inner residential areas, $c$ housing estates and $e$ industrial areas in 1987, 2003 and 2011

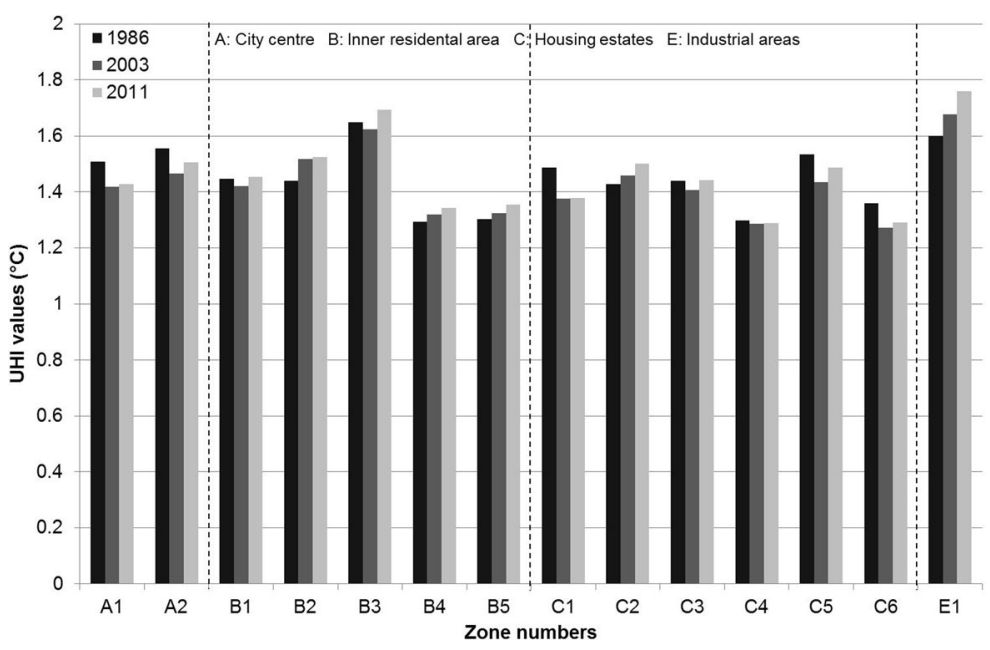

ratio decreased for housing areas between 1987 and 2003 (Fig. 5). When housing construction finished in the 1980s, open green areas were formed on the sites of construction debris. Therefore, the decrease in impervious surface ratios actually represents the increase in green areas. This process is shown in Fig. 10.

Madhavan et al. (2001) studied the ratio of V-I-S components along straight lines radiating from the city centre. The study similarly explained the decrease in impervious surface ratios with the growth of vegetation and the increase of reconstruction.

Impervious surface areas increased mostly in the outskirts, including suburban residential areas. Construction began in the 1990s on parcels lying outside the city core because areas within the round dam were unavailable and densely built up. Large investment projects in the industrial area first appeared in the 1990s. Construction of industrial buildings (factories, warehouses) have high values on difference maps (25$100 \%$ ), with more than a $1 \%$ increase on zone maps (Fig. 5).

Heat emission increases due to built-up density can be detected and monitored on the urban heat island intensity maps derived from impervious surface ratio maps (Fig. 7). In previous studies, UHI values were calculated using different indicators derived from the LST (Chen et al. 2006; Zhang and Wang 2008; Schwarz et al. 2011). In our study, a linear regression relationship was used between the ratio of built-up density and urban heat island intensity in Szeged. In previous Szeged studies (Unger et al. 2001), heat island intensity spatial distribution maps had one centre a)

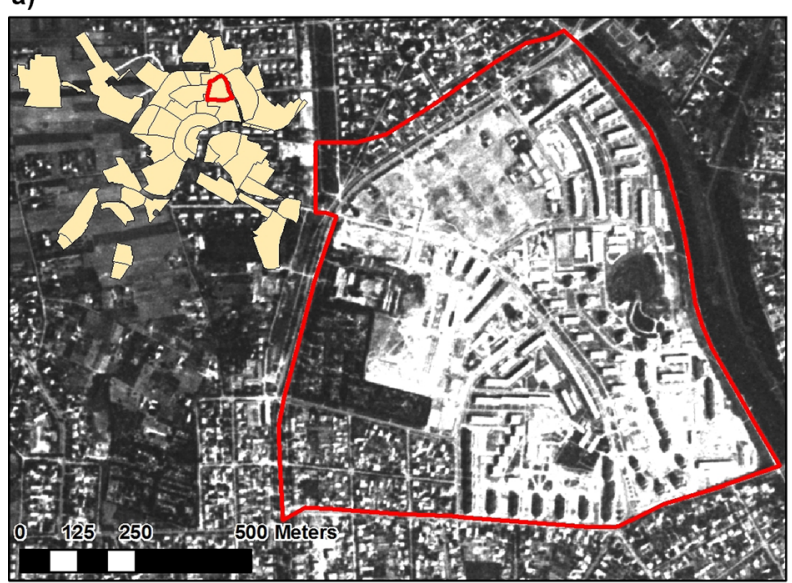

b)

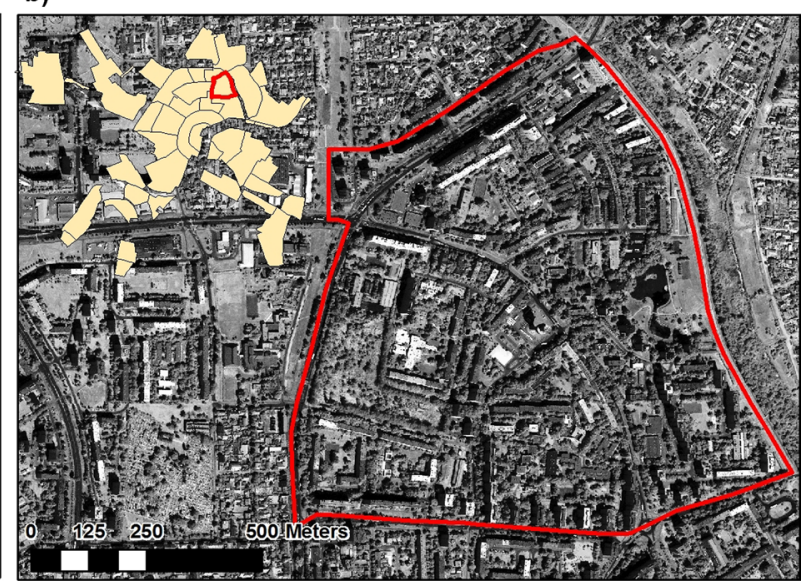

Fig. 10 Formation of green areas in housing estates. a CORONA satellite image acquired in 1972. b IKONOS satellite image acquired on 23 August 2004 
(maximum), which was located at the city centre and was surrounded concentrically by isotherms. In our study, a two-centred maximum was observed in 1987 , and then in 2003 and 2011, a one-centred maximum with smaller local maximums was observed. The maximums were located both in the city centre and in the industrial area. Minor local maximums appear in housing estates in the northeastern part of the city, as well as in the inner residential area in the southern part of the city (residential park, shopping centre). The cooling effect of the Tisza River can be seen on the heat island intensity maps. This separates the maximum of the city centre from the heat excess of the industrial area to the east of the Tisza River.

Temperatures decreased in the city centre and the housing estates due to vegetation growth and, therefore, to the "decrease" in impervious surfaces. The mean temperatures in the industrial area increased from 1987 (by $0.07{ }^{\circ} \mathrm{C}$ ) due to significant construction in large open areas. Mean temperatures increased from 1987 by $0.04-0.08{ }^{\circ} \mathrm{C}$ in the inner residential areas due to a $1-5 \%$ increase in built-up density. The UHI intensity values and the shape of the heat islands changed during our study period (1987-2011). Figure 7 shows that in 1987, the UHI maximum on the northwestern-southeastern axis of the industrial area and the city centre had two centres of $1.8-1.9^{\circ} \mathrm{C}$. In 2003 , the two centres moved closer together due to the increasing impervious surface ratio in the industrial area and the decreasing ratio in the city centre. In addition, the centres shifted northwest. The mean temperature was greater than that in the outskirts by $1.7-1.8^{\circ} \mathrm{C}$. Both the maxima of the city centre and the housing estates decreased due to the increase in green areas and due to the planning of green areas in housing estates. The minimum between housing estate districts $\mathrm{C} 1$ and $\mathrm{C} 2$ and the city centre disappeared due to condominium and mall constructions. Therefore, the existing ventilation zone began to shrink.

Between 2003 and 2011, the urban heat island maximum located in the city centre and the industrial area had only one centrum, which was shifted towards the industrial area. The mean temperature of this maximum was $2{ }^{\circ} \mathrm{C}$. This affected only a small proportion of the inhabitants because less than $1 \%$ of the population lived there (1002 inhabitants), whereas the maximum in the city centre influenced the comfort of 20,530 inhabitants $(12.2 \%)$. The housing estate maximum in the northeastern part of the city expanded closer to this shape. Its local maximum $\left(1.7^{\circ} \mathrm{C}\right)$ was shifted towards district $\mathrm{C} 2$, which affected 10,724 inhabitants due to its dense population. The mean temperature increased further in districts $\mathrm{B} 1$ and $\mathrm{B} 2$ of the inner residential area, and the local maximum was focused on a higher built-up density. The ratio of built-up density increased due to significant construction, but the surrounding areas remained mostly low to moderate density. Therefore, the minimum $\left(0.8-1.1^{\circ} \mathrm{C}\right)$ caused by the green area of the Szeged Zoo also grew narrower between the industrial area and the southern part of the city. A smaller increase in intensity values is observed to the east of the Tisza River, but construction mostly began on areas outside of the grid network and their effect is only partially shown.

\section{Conclusions}

The results demonstrated that the change in impervious surface ratios in census districts during the last 25 years can be accurately mapped by spectral mixture analysis based on Landsat images. The significant built-up changes were evaluated and monitored in each census district by using impervious surface change maps and zone statistics. These significant changes were (1) condominium construction in the inner residential areas since the 1990s; (2) formation of large open green areas in housing estates after construction and the construction of shopping centres and commercial and service provider buildings; (3) continuous increases in built-up areas in the industrial zone from 1980 to 2011; (4) and increases in built-up density in suburban residential areas.

The spatial distribution of urban heat island intensity was effectively mapped by a linear regression equation based on the impervious surface ratio maps. In addition, the changes in the UHI values from the 1980s were monitored by a time series analysis. It was observed that (1) the centrum of the modelled urban heat island shifted towards the direction of the industrial area; (2) a new local maximum was formed and continued to grow due to the significant build-up in the southern part of the city; and (3) areas with lower temperatures between housing estates and the city centre are shrinking. However, existing "cooler" areas were also detected, such as the Szeged Zoo, the Tisza River, and an inner residential area with traditionally built-up density in the southern part of the city. Decreasing the northwestern-southeastern maximum by developing green areas and lines of 
trees, as well as increasing the proportion of green areas in the southern part of the city, would be of great importance for urban planning programs.

In summary, long period satellite data series can be produced based on Landsat images; Landsat Operational Land Imager (Landsat OLI) data may also be included. This study showed that lower spatial resolution satellite data can provide information about changes in urban ecosystems at the district level. The effects of built-up density can be monitored using impervious surface and heat island intensity maps derived from Landsat satellite data series. In future research, the database can be expanded by adding ratio maps of the vegetation and the corresponding derived indicators (the extension of green areas, the ratio of biologically inactive areas and the amount of green surfaces associated with the number of inhabitants). In our study, different vegetation phenologies caused uncertainties in deriving an impervious surface ratio. Future research directions can include the analysis of seasonal differences in impervious surface ratios caused by different seasonal acquisition dates.

Acknowledgements We would like to thank the Department of Climatology and Landscape Ecology at the University of Szeged for providing UHI intensity data collected by mobile observations in Szeged.

\section{References}

Adams, J. B., Smith, M. O., \& Johnson, P. E. (1986). Spectral mixture modeling: a new analysis of rock and soil types at the Viking Lander 1 site. Journal of Geophysical Research, 91(8), 8098-8112.

Bauer, M. E., Loffelholz, B. C., \& Wilson, B. (2007). Estimating and mapping impervious surface area by regression analysis of Landsat imagery. In Q. Weng (Ed.), Remote sensing of impervious surfaces (pp. 3-19). Boca Raton, Florida: CRC Press.

Blazovich, L. (2005). (1943-) Szeged rövid története (Brief history of Szeged), Szeged Csongrád megyei levéltár.

Borel, C. C., \& Gerstl, S. A. W. (1994). Nonlinear spectral mixing models for vegetative and soil surfaces. Remote Sensing of Environment, 47(3), 403-416.

Chander, G., \& Markham, B. L. (2003). Revised Landsat-5 TM radiometric calibration procedures, and postcalibration dynamic ranges. IEEE Transactions on Geoscience and Remote Sensing, 41(11), 2674-2677.

Chavez Jr., P. S. (1996). Image-based atmospheric correctionsrevisited and improved. Photogrammetric Engineering and Remote Sensing, 62(9), 1025-1036.
Chen, X. L., Zhao, H. M., Li, P. X., \& Yin, Z. Y. (2006). Remote sensing image-based analysis of the relationship between urban heat island and land use/cover changes. Remote Sensing of Environment, 104(2), 133-146.

Chormanski, J., Voorde, T. V. D., Roeck, T. D., Batelaan, O., \& Canters, F. (2008). Improving distributed runoff prediction in urbanized catchments with remote sensing based estimates of impervious surface cover. Sensors, 8(2), 910-932.

Cracknell, A. P. (1998). Synergy in remote sensing-What's in a pixel? International Journal of Remote Sensing, 19(11), 2025-2047.

Deng, C., \& Wu, C. (2013). Examining the impacts of urban biophysical compositions on surface urban heat island: a spectral unmixing and thermal mixing approach. Remote Sensing of Environment, 131, 262-274.

Dewan, A. M., \& Yamaguchi, Y. (2009). Using remote sensing and GIS to detect and monitor land use and land cover change in Dhaka metropolitan of Bangladesh during 1960-2005. Environmental Monitoring and Assessment, 185(2), 16991709.

Elvidge, C. D., Baugh, K. E., Kihn, E. A., Kroehl, H. W., Davis, E. R., \& Davis, C. W. (1997). Relation between satellite observed visible-near infrared emissions, population, economic activity and electric power consumption. International Journal of Remote Sensing, 18(6), 1373-1379.

Franke, J., Roberts, D. A., Halligan, K., \& Menz, G. (2009). Hierarchical multiple endmember spectral mixture analysis (MESMA) of hyperspectral imagery for urban environments. Remote Sensing of Environment, 113(8), 1712-1723.

Geymen, A., \& Baz, I. (2007). Monitoring urban growth and detecting land-cover changes on the Istanbul metropolitan area. Environmental Monitoring and Assessment, 136(1), 449-459.

Henits, L., Jürgens, C., \& Mucsi, L. (2016). Seasonal multitemporal land-cover classification and change detection analysis of Bochum, Germany, using multitemporal Landsat TM data. International Journal of Remote Sensing. doi:10.1080/01431161.2015.1125558.

Hungarian Central Statistical Office. (2012). Magyarország közigazgatási helynévkönyve, Központi Statisztikai Hivatal. Budapest, 2012, 228.

Imhoff, M. L., Zhang, P., Wolfe, R. E., \& Bounoua, L. (2010). Remote sensing of the urban heat island effect across biomes in the continental USA. Remote Sensing of Environment, 114, 504-513.

Jianyaa, G., Haiganga, S., Guoruia, M., \& Qimingb, Z. (2008). A review of multi-temporal remote sensing data change detection algorithms (pp. 757-762). Beijing: ISPRS Congress.

Li, G., \& Weng, Q. (2007). Measuring the quality of life in city of Indianapolis by integration of remote sensing and census data. International Journal of Remote Sensing, 28(2), 249-267.

Li, J., Song, C., Cao, L., Zhu, F., Meng, X., \& Wu, J. (2011). Impacts of landscape structure on surface urban heat islands: a case study of Shanghai, China. Remote Sensing of Environment, 115, 3249-3263.

Lo, C. P., \& Faber, B. J. (1997). Integration of Landsat Thematic Mapper and census data for quality of life assessment. Remote Sensing of Environment, 62(2), 143-157.

Lu, D., Mausel, P., Brondízio, E., \& Moran, E. (2004). Change detection techniques. International Journal of Remote Sensing, 25(12), 2365-2401. 
Lu, D., \& Weng, Q. (2006a). Use of impervious surface in urban land-use classification. Remote Sensing of Environment, 102(1-2), 146-160.

Lu, D., \& Weng, Q. (2006b). Spectral mixture analysis of ASTER images for examining the relationship between urban thermal features and biophysical descriptors in Indianapolis, Indiana, USA. Remote Sensing of Environment, 104(2), 157-167.

Lu, D., Weng, Q., \& Li, G. (2006). Residential population estimation using a remote sensing derived impervious surface approach. International Journal of Remote Sensing, 27(16), 3553-3570.

Madhavan, B. B., Kubo, S., Kurisaki, N., \& Sivakumar, T. V. L. N. (2001). Appraising the anatomy and spatial growth of the Bangkok metropolitan area using a vegetation-impervioussoil model through remote sensing. International Journal of Remote Sensing, 22(5), 789-806.

Mesev, V. (1998). The use of census data in urban image classification. Photogrammetric Engineering and Remote Sensing, 64(5), 431-438.

Michishita, R., Jiang, Z., \& Xu, B. (2012). Monitoring two decades of urbanization in the Poyang Lake area, China through spectral unmixing. Remote Sensing of Environment, 117, 3-18.

Rashed, T., Weeks, J. R., \& Gallada, M. S. (2001). Revealing the anatomy of cities through spectral mixture analysis of multispectral satellite imagery: a case study of the greater Cairo region, Egypt. Geocarto International, 16(4), 5-15.

Rashed, T., Weeks, J. R., Stow, D., \& Fugate, D. (2005). Measuring temporal compositions of urban morphology through spectral mixture analysis: toward a soft approach to change analysis in crowded cities. International Journal of Remote Sensing, 26(4), 699-718.

Ridd, M. K. (1995). Exploring a VIS (vegetation-impervious surface-soil) model for urban ecosystem analysis through remote sensing: comparative anatomy for cities. International Journal of Remote Sensing, 16(12), 2165-2185.

Roberts, D. A., Gardner, M., Church, R., Ustin, S., Scheer, G., \& Green, R. O. (1998). Mapping chaparral in the Santa Monica mountains using multiple endmember spectral mixture models. Remote Sensing of Environment, 65(3), 267-279.

Schneider, A. (2012). Monitoring land cover change in urban and peri-urban areas using dense time stacks of Landsat satellite data and a data mining approach. Remote Sensing of Environment, 124, 689-704.

Schwarz, N., Lautenbach, S., \& Seppelt, R. (2011). Exploring indicators for quantifying surface urban heat islands of European cities with MODIS land surface temperatures. Remote Sensing of Environment, 115(12), 3175-3186.

Setiawan, H., Mathieu, R., \& Thompson-Fawcett, M. (2006). Assessing the applicability of the V-I-S model to map urban land use in the developing world: case study of Yogyakarta, Indonesia. Computers, Environment and Urban Systems, 30(4), 503-522.

Sharma, R., Ghosh, A., \& Joshi, P. K. (2013). Spatio-temporal footprints of urbanisation in Surat, the Diamond City of India (1990-2009). Environmental Monitoring and Assessment, 185(4), 3313-3325.

Small, C. (2002). Multitemporal analysis of urban reflectance. Remote Sensing of Environment, 81(2-3), 427-442.

Small, C., \& Lu, J. (2006). Estimation and vicarious validation abundance by spectral mixture analysis. Remote Sensing of Environment, 100(4), 441-456.
Smith, M. O., Johnson, P. E., \& Adams, J. B. (1985). Quantitative determination of mineral types and abundances from reflectance spectra using principal components analysis. Journal of Geophysical Research, 90, 792-804.

Smith, M. O., Ustin, S. L., Adams, J. B., \& Gillespie, A. R. (1990). Vegetation in deserts: I. A regional measure of abundance from multispectral images. Remote Sensing of Environment, 31(1), 1-26.

Song, C., \& Woodcock, C. E. (2003). Monitoring forest succession with multitemporal Landsat images: factors of uncertainty. IEEE Transactions on Geoscience and Remote Sensing, 41(11), 2557-2567.

Unger, J., Bottyán, Z., Sümeghy, Z., \& Gulyás, Á. (2000). Urban heat island development affected by urban surface factors. Idojjárás, 104, 253-268.

Unger, J., Sümeghy, Z., Gulyás, Á., Bottyán, Z., \& Mucsi, L. (2001). Land-use and meteorological aspects of the urban heat island. Meteorological Applications, 8, 189-194.

United Nations (2014). World urbanization prospects the 2014 revision, World Urbanization Prospects, Department of Economic and Social Affairs, Population Division 2014.

Vogt, J. A., \& Oke, T. R. (2003). Thermal remote sensing of urban climates. Remote Sensing of Environment, 86(3), 370-384.

Weng, Q., \& Hu, X. (2008). Medium spatial resolution satellite imagery for estimating and mapping urban impervious surfaces using LSMA and ANN. IEEE Transaction on Geosciences and Remote Sensing, 46(8), 2397-2406.

Weng, Q., \& Lu, D. (2008). A sub-pixel analysis of urbanization effect on land surface temperature and its interplay with impervious surface and vegetation coverage in Indianapolis, United States. International Journal of Applied Earth Observation and Geoinformation, 10(1), 68-83.

Wu, C., \& Murray, A. T. (2003). Estimating impervious surface distribution by spectral mixture analysis. Remote Sensing of Environment, 84(4), 493-505.

$\mathrm{Wu}, \mathrm{C}$. (2004). Normalized spectral mixture analysis for monitoring urban composition using ETM+ imagery. Remote Sensing of Environment, 93(4), 480-492.

Wu, C., \& Yuan, F. (2007). Seasonal sensitivity analysis of impervious surface estimation with satellite imagery. Photogrammetric Engineering \& Remote Sensing, 73(12), 1393-1402.

Xian, G., \& Crane, M. (2006). An analysis of urban thermal characteristics and associated land cover in Tampa Bay and Las Vegas using Landsat satellite data. Remote Sensing of Environment, 104(2), 147-156.

Yuan, F., \& Bauer, M. B. (2007). Comparison of impervious surface area and normalized difference vegetation index as indicators of surface urban heat island effects in Landsat imagery. Remote Sensing of Environment, 106(3), 375-386.

Yuan, F., Wu, C., \& Bauer, M. E. (2008). Comparison of spectral analysis techniques for impervious surface estimation using Landsat imagery. Photogrammetric Engineering and Remote Sensing, 74(8), 1045-1055.

Zhang, J. Q., \& Wang, Y. P. (2008). Study of the relationships between the spatial extent of surface urban heat islands and urban characteristic factors based on Landsat ETM plus data. Sensors, 8(11), 7453-7468. 